\title{
Experimental Study on RFID Antenna Reading Areas in a Tunnel System
}

\author{
Kai Kordelin, ${ }^{1}$ Jaana Kordelin, ${ }^{1}$ Markku Johansson, ${ }^{2}$ Johanna Virkki, \\ Leena Ukkonen, ${ }^{1}$ and Lauri Sydänheimo ${ }^{1}$ \\ ${ }^{1}$ BioMediTech Institute and Faculty of Biomedical Sciences and Engineering, Tampere University of Technology, Tampere, Finland \\ ${ }^{2}$ Aitosolutions Oyj, Kangasala, Finland \\ Correspondence should be addressed to Kai Kordelin; kai@kordelin.eu
}

Received 14 March 2017; Accepted 27 July 2017; Published 30 August 2017

Academic Editor: Yuh-Shyan Hwang

Copyright (C) 2017 Kai Kordelin et al. This is an open access article distributed under the Creative Commons Attribution License, which permits unrestricted use, distribution, and reproduction in any medium, provided the original work is properly cited.

We study optimized antenna reading area mappings for a radiofrequency identification- (RFID-) based access monitoring system, used in an underground nuclear waste storage facility. We shortly introduce the access monitoring system developed for the ONKALO tunnel in Finland and describe the antenna mounting points as well as the research area. Finally, we study the measurement results of the antenna reading areas and factors that affect the reading area size. Based on our results, in addition to antenna location and direction, absorption to obstacles, reflections, diffraction, scattering, and refraction affect the antenna reading area.

\section{Introduction}

The spent nuclear fuel accumulated from the Finnish nuclear power plants will be disposed in Olkiluoto, Finland, in a tunnel system known as "ONKALO." The purpose of ONKALO is to ensure that the bed rock in Olkiluoto is suitable for the final storage of the used nuclear fuel. Versatile research has been conducted there since the beginning of its construction. The nuclear waste facilities consist of an encapsulation plant, constructed to encapsulate the spent nuclear fuel; a disposal facility, consisting of an underground repository and other underground rooms; and the above ground service spaces. Access routes to the disposal facility are an inclined access tunnel and vertical shafts. As underground tunnels are usually structurally nonuniform, with a network of interconnected tunnels, crosscuts, shafts, escape ways, first-aid stations, alcoves, and tunnel block-ages, monitoring the access to the tunnel plays a critical part in the work safety [1]. In the deposition area of ONKALO, two parallel central tunnels connect all the deposition tunnels and these central tunnels are interconnected at regular intervals [2].

The developed radiofrequency identification- (RFID-) based access monitoring system was created to increase and upkeep work safety. Its purpose is to know how many persons are located inside ONKALO in a case of an accident. In emergency situations, underground personnel and equipment identification and localization are critical [3-5]. RFID technology is a wireless, contactless technology that provides efficient solutions for identification, warehousing, and logistics and also for reliable and easy access monitoring [6-8]. A comprehensive introduction to today's systems and standardization is provided in [9-12].

There are no specific instructions for the placement and the direction of RFID antennas in an underground tunnel. With good design it is possible to create optimal antenna geometry for an underground tunnel but this kind of optimized antenna works only in the designed point [13], and there is no systematically studied information available on how radio waves propagate in a tunnel. A radio signal is reflected from the walls of the tunnels creating many different propagation paths [14]. The main problems with tunnels are the uneven wall surfaces that cause reflections and disturb radio waves. The final antenna locations and direction can be done only by trial and error. This is also how it was done in ONKALO and the purpose of this study is to introduce how 


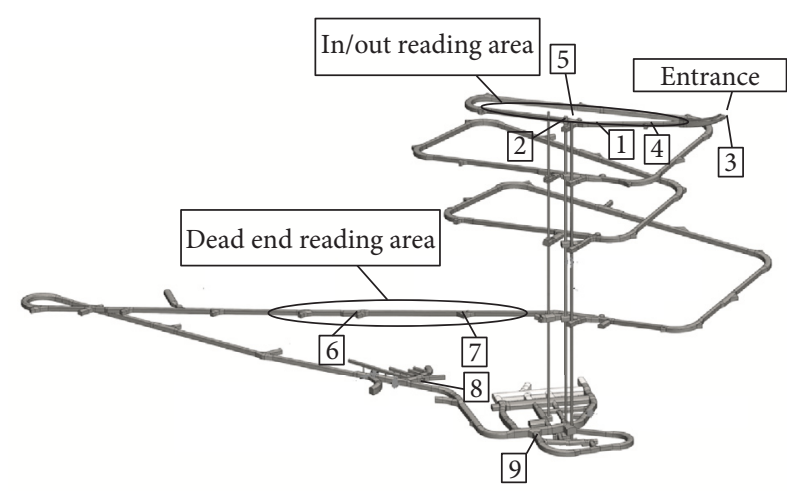

FIGURE 1: The reading points and reading areas in ONKALO.

the optimized antenna reading area mappings were done in this underground nuclear waste storage facility.

This paper is organized as follows. After Introduction, the ONKALO RFID system and equipment are shortly presented in Section 2. Section 3 introduces the research area and the research plan. In Section 4, the antenna installation points are given and in Section 5 the measurement plans and implementation of the measurements are described. Section 6 presents the antennas measurement results and describes the features that affect the antenna reading area size. Finally, in Section 7 , the conclusions of this study are gathered together.

\section{ONKALO RFID System and Equipment}

There are two different information reading areas at ONKALO (See Figure 1). A reading area consists of reading points that give information from both directions of traffic. The first reading area is at the entry of ONKALO. It monitors the traffic going in and out of ONKALO. This reading area has four reading points. The second reading area, with two reading points, is located at the "dead end" and it controls the traffic going in and out of that area. The use of the RFID system and its reliability in ONKALO has been studied for many years [15].

In addition to the given reading areas, there are three additional reading points. One is located in the demonstration area and another at the technical level. The third reading point is at the beginning of the drive ramp, before the entrance to ONKALO.

A reading point consists of a reader and antenna. The reader is only used for reading information; it does not transmit anything. The active RFID tag, that is, ID card, is the only transponder in the system. The process of identification is the same at ONKALOs both reading areas and all reading points. In practice, when a vehicle, as well as people inside it, comes to a reading point area, the reader identifies the ID numbers of the vehicle and the people and records them to the system database.

The readers are Wavetrend L-RX201 RFID readers (Figure 2). The readers have been linked to the system with integrated computers. The readers' sensitivity, that is, threshold value, has been adjusted by program to 65 . According to the RX201 manual, the readers RSSI (received signal strength

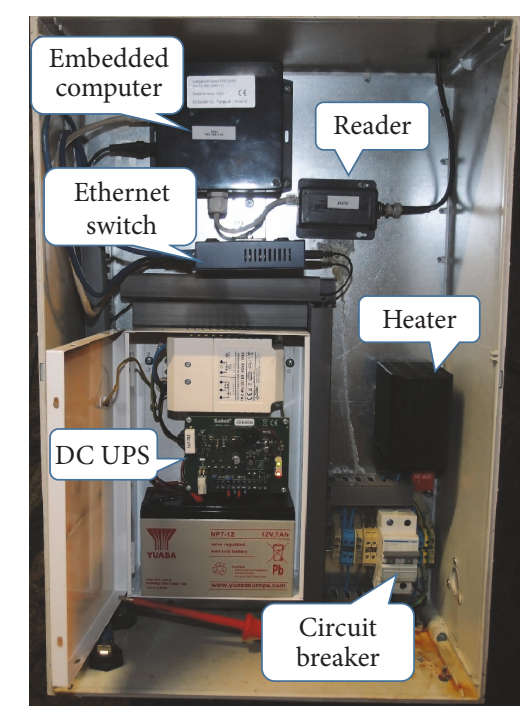

FIGURE 2: Reader with integrated computer.

indicator) can be adjusted between 60 and 120, where 60 is the RSSI maximum sensitivity. The L-RX201 maximum sensitivity is $-103 \mathrm{dBm}$, which means that RSSI 60 would be equal to $-103 \mathrm{dBm}$. No other $\mathrm{dBm}$ values are given and thus it is not possible to make a conversion chart between RSSI and received power.

The used antennas are TwinGain ${ }^{\mathrm{TM}} 434$ directional antennas (Figure 3). The antenna polarization has been informed to be circular, but its reading area is more elliptical. The protection class of the antenna is IP 65. The antenna cable determines the maximum distance between the reader and antenna, which cannot exceed ten meters. The used antenna was initially measured in an anechoic chamber in laboratory environment. In Figure 4, the radiation pattern of the antenna is shown in horizontal and vertical directions. The systems integrated computer is a Raspberry PI Model B, a one-circuit board computer that has a $700 \mathrm{MHz}$ ARM11 processor and 512 MB memory.

The Wavetrend manufactured RFID identificators with active chips using a $434 \mathrm{MHz}$ frequency are used in the ONKALO as ID cards (Figure 3). Each card sends its own ID number once every 1.5 seconds. The ID card is a beacon type tag that can be read only when it sends its own ID number. The card is inside a $85 \mathrm{~mm}$ long, $55 \mathrm{~mm}$ wide, and $5 \mathrm{~mm}$ thick plastic holder.

The tunnel identification program is HorusWindow applications logic program by Elcoplast (Figure 5). The application logic fulfills all tasks given by the program and saves the data to the database. The application logic does not have its own interface, so a web application has been created. The web application and the application logic are not directly connected, as all data goes through the database service (SQL Server).

\section{Research Area and Research Plan}

The object of this paper is to study how radio waves propagate in a tunnel. The ONKALO upper end, that is, so-called in/out 


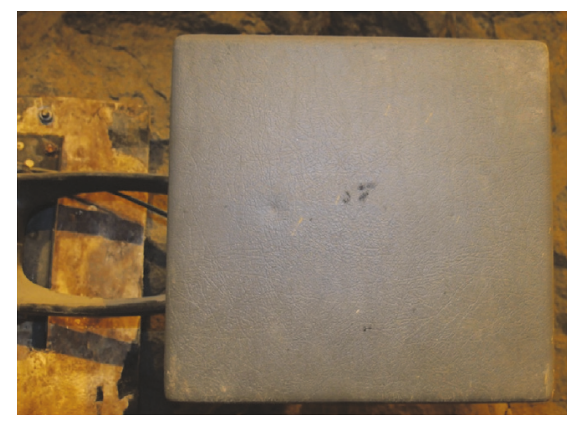

(a)

FIgURE 3: Directional antenna (a) and active ID card (b).

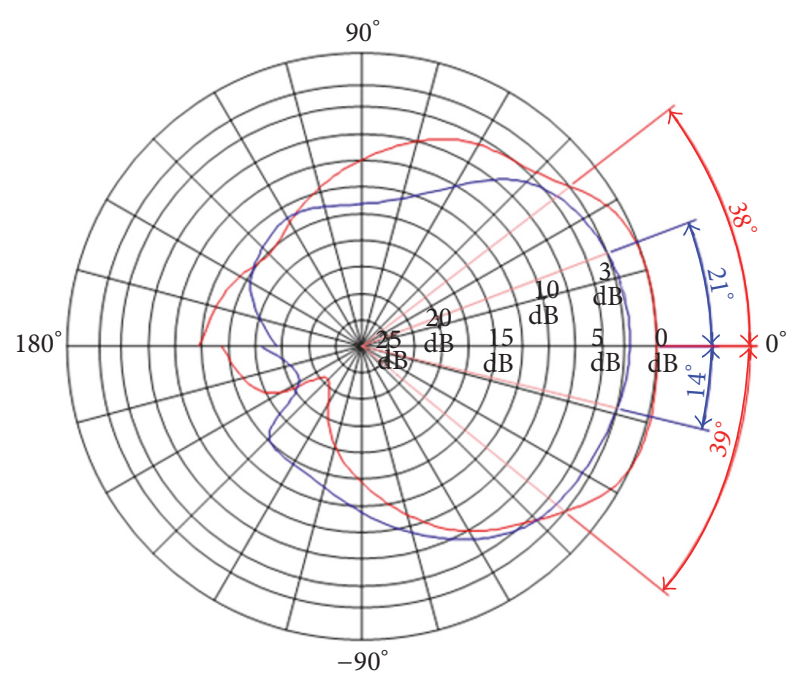

FIGURE 4: Horizontal and vertical radiation patterns of the antenna. The $-3 \mathrm{~dB}$ ring is marked with the opening angles of both measurements.

reading area, was selected as the research area. This area is marked in Figure 6. The reading area consists of three different readers and antennas.

The ID tags were installed to the safety cones while doing the measurements (See Figure 7). By this method the ID tag could be set to a height of 1 meter. Firstly, safety cones with ID cards attached to them were brought into the ONKALO tunnel system, and they were placed to the reading area for reading tests. Screenshots of the readings were taken of the HorusWindows identification program. By examining these measurement records, it was possible to get a good idea on how the antennas were working in each place.

\section{Reader Antenna Installation Points}

As there initially was no official installation guide for the antenna placement, the antennas were installed by considering the tunnel decline and vehicle size. The installation location information has been given by pole number, which means the current points distance (in meters) from the tunnel opening. Pole 0 is located at the entrance. A pole number with

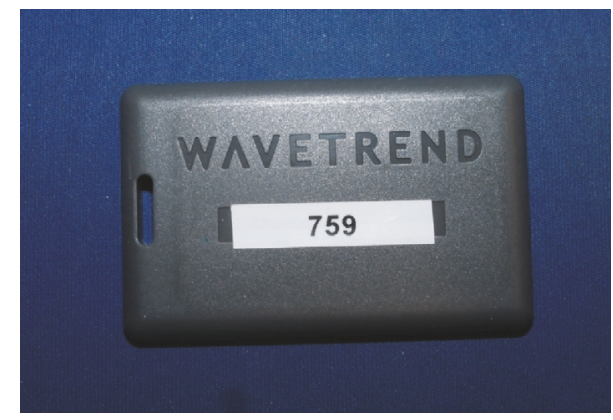

(b)

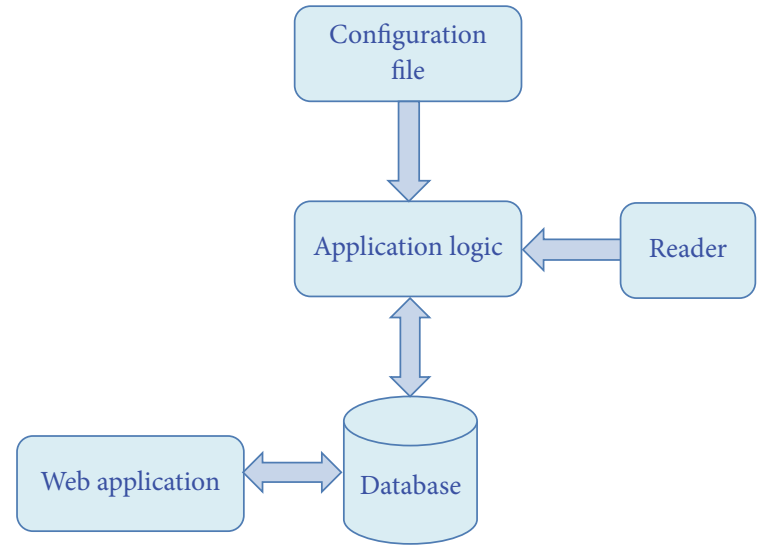

FIgURE 5: Program description.

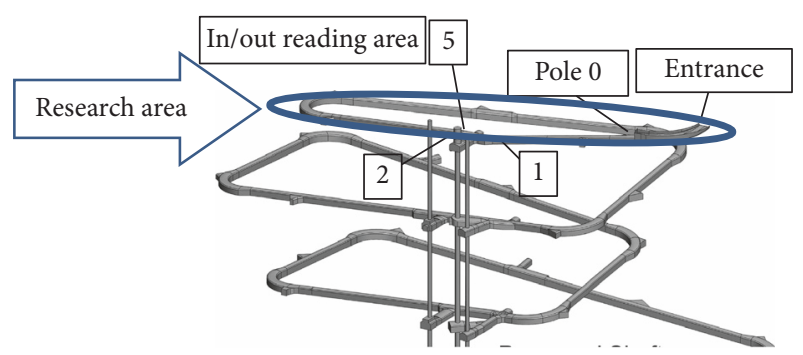

FIGURE 6: Research area, reading points, and reading areas in ONKALO.

$\mathrm{a}+$ in front of it means that it is located before the actual tunnel opening.

4.1. Ingoing Traffic Reading Antenna Installation Point. Reader antenna 1, that is, the antenna that reads traffic going into ONKALO, is installed on a firewall at pole number 95 (See Figure 14). The firewall is built from PAROC elements. PAROC elements are called sandwich elements because of their structure (See Figure 8) and the elements consist of a PAROC structural stone fiber core. Thin metal sheets have been glued on to the stone fiber core, which creates a very 


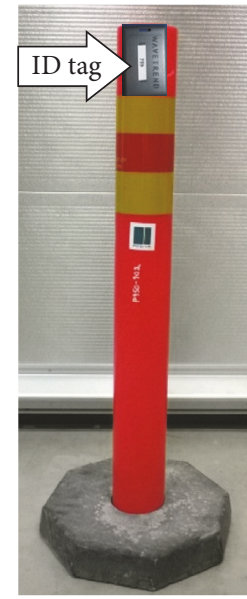

Figure 7: Safety cone.

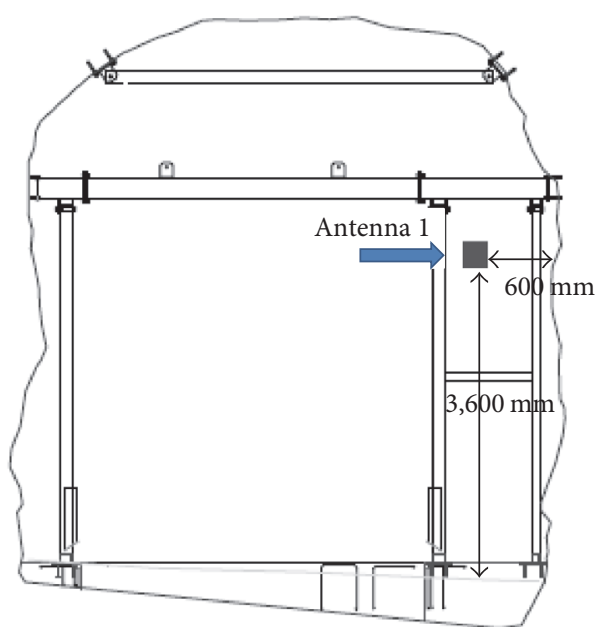

(a)

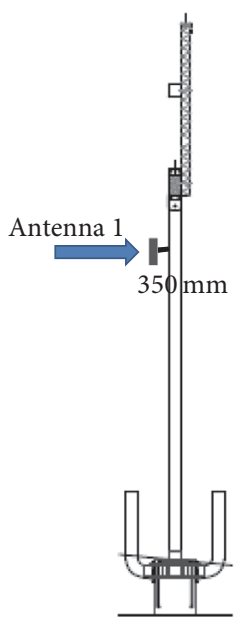

(b)

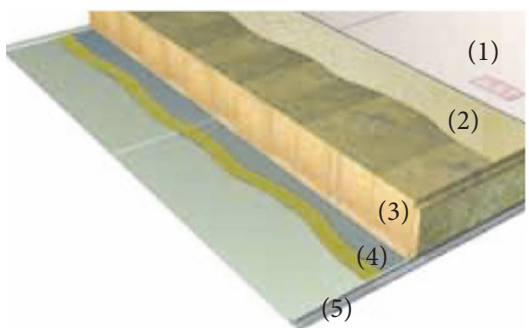

(1) Substrate-coated steel sheets

(2) Strong and durable adhesive

(3) Noncombustible core of PAROC structural stone wool lamellas

(4) Multilayer primer to ensure the bonding between the adhesive and the steel sheet

(5) Fire safe and tight joint design

(c)

FIGURE 8: Firewall construction at pole 95 from the front (a) and from the side (b) and the firewall PAROC-element structure (c). 


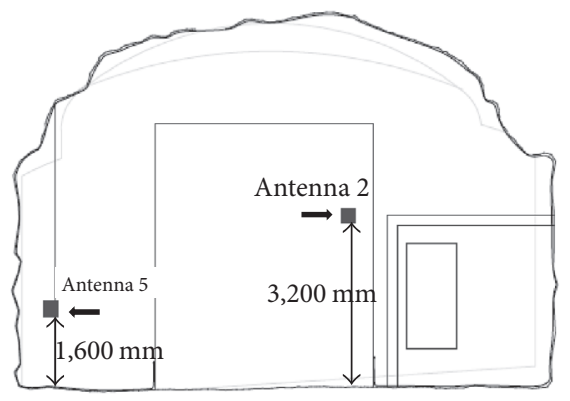

(a)

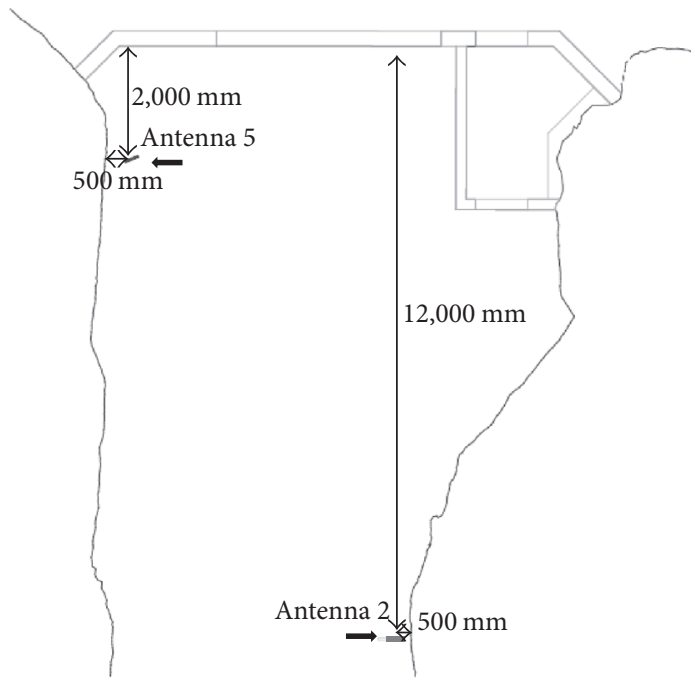

(b)

Figure 9: The front side of the concrete wall at pole 150 with antennas 2 and 5 (a) and the top side of the concrete wall at pole 150 with antennas 2 and 5 (b).

strong composite structure [16]. The element used in ONKALO has a $U$ value of $0.36 \mathrm{~W} / \mathrm{m}^{2} \mathrm{~K}$ and a density of $21 \mathrm{~kg} / \mathrm{m}^{2}$. The antenna is placed $350 \mathrm{~mm}$ from the firewall and the installation height is $3600 \mathrm{~mm}$. The antenna is $600 \mathrm{~mm}$ away from the tunnel wall, as presented in Figure 8.

\subsection{Outgoing Traffic Reading Antenna Installation Points.} Both antennas reading outgoing traffic are attached to the sidewall of the ONKALO tunnel. It was not possible to install the antennas to the concrete structures (shown in Figure 8) as at that point they were not built yet, but the wall was ready when these measurements were conducted.

Reader antenna 2 is attached to the left wall at pole 162 . It is mounted $12,000 \mathrm{~mm}$ from the concrete wall and at height of $3200 \mathrm{~mm}$ from the ground. The side of the antenna is $500 \mathrm{~mm}$ from the tunnel rock wall. There is no wall structure behind the antenna, only the driveway. Reader antenna 5 is installed to the right hand side wall at pole 152 . It is mounted $2,000 \mathrm{~mm}$ from the concrete wall and its height from the ground is $1600 \mathrm{~mm}$. The side of the antenna is $500 \mathrm{~mm}$ from the tunnel rock wall (Figure 9).
The concrete wall behind the antennas has been done by pressure insertion. It is a $300 \mathrm{~mm}$ thick sectioning firewall (presented in Figure 9) and has a double rebar (stainless steel) net with $200 \mathrm{~mm}$ gaps. It has a $4200 \mathrm{~mm}$ wide and $5100 \mathrm{~mm}$ high section without rebar for the driveway.

\section{Measurements}

The idea of these measurements was to make a preliminary study towards a model for the best antenna location in tunnel conditions. Four measurement configurations were made for the research as the first configurations turned out to be insufficient and results indicated that more detailed measurements were necessary.

5.1. Measurement Configurations. At its widest the measurements covered the area from Pole 320 to the drive ramp upper end at pole +70 . The measurement points have been marked to the ONKALO layout in Figure 14.

Measurement Configuration 1. Measurement configuration 1 consisted of antennas 1,2, and 5. Safety cones with ID tags 


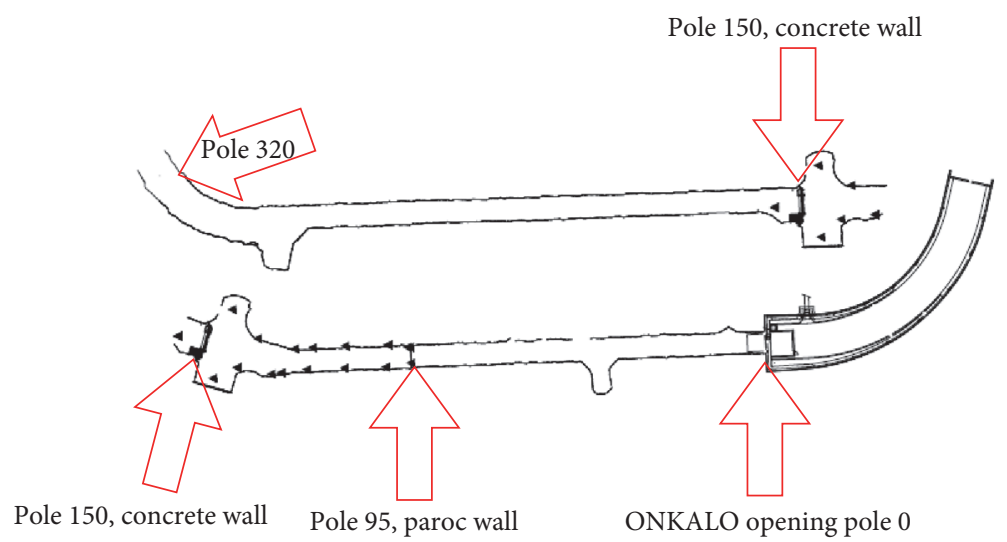

FIGURE 10: Measurement configuration 1.

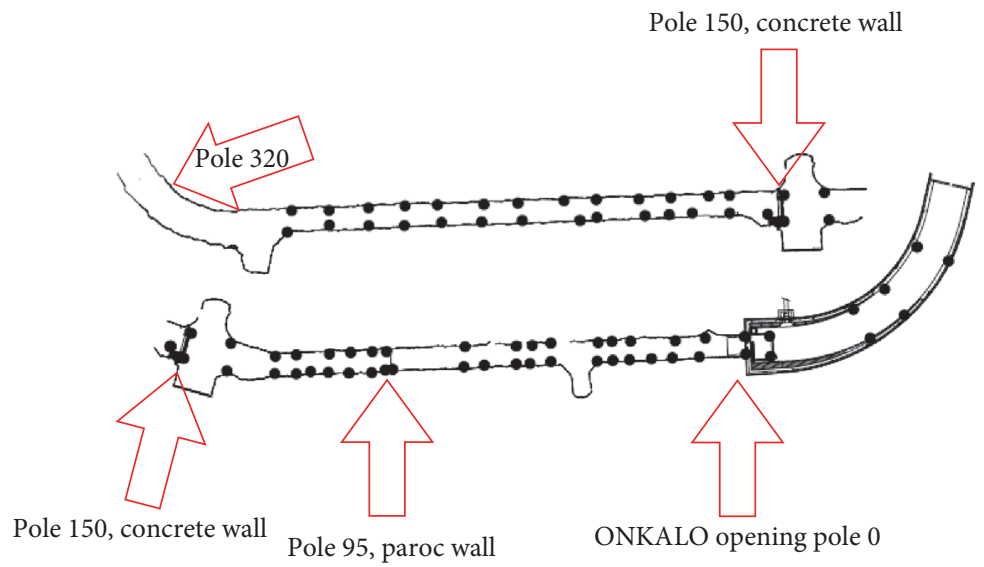

FIGURE 11: Measurement configuration 2.

were set on both sides of the ONKALO driveway between poles 95 and 155 . The purpose of this measurement plan was to map the reader's rear area. Measurement plan 1 has been marked by triangles in Figures 10 and 14. During the measurements it was noticed that the scope was too narrow to confirm if the antennas worked properly.

Measurement Configuration 2. Measurement configuration 2 consisted of antennas 1, 2, and 5 full reading range, including both frontal and rear area. Safety cones with ID tags were set on both sides of the ONKALO driveway between poles +55 and 280. Plan 2 has been marked by circles in Figures 11 and 14 . The reason why measurement plan 3 was considered necessary was the fact that the frontal reading area of the antennas was larger than anticipated.

Measurement Configuration 3. This measurement configuration was done deeper in the ONKALO tunnel system. The furthest measuring points were located at the left side of the driveway at pole 320 and on the right side of pole 310 . The whole measurement area consisted of the poles from 0 to 320 . From these measurements it was possible to get the driveways' both sides' maximum reading area. Plan 3 has been marked by squares in Figures 12 and 14. During the measurements, it was noticed that the results from the driveways' left and right sides differed, which resulted in measurement configuration 4 .

Measurement Configuration 4. Measurement configuration 4 consisted of measuring the ONKALO driveways' middle section. The measurement started from pole +70 and ended at pole 320. Plan 4 has been marked by stars in Figures 13 and 14. These measurements gave sufficient data for the antenna middle section reading areas.

5.2. Measurement Implementation. Authenticating the measurements was difficult as readings from various antennas came almost constantly. The HorusWindows program does not save the readings but shows them only in real time (see Figure 15). For this reason, the only way to get real time data was taking screenshots of the display. These screenshots were saved in the measurement program to their specific places with given names. The measurement plan also had all ID numbers of the tags. By combining these two factors it was possible to get the tag location in the ONKALO tunnel. If the print screen file did not contain the ID card number, it meant the antennas had not recognized that specific tag. 


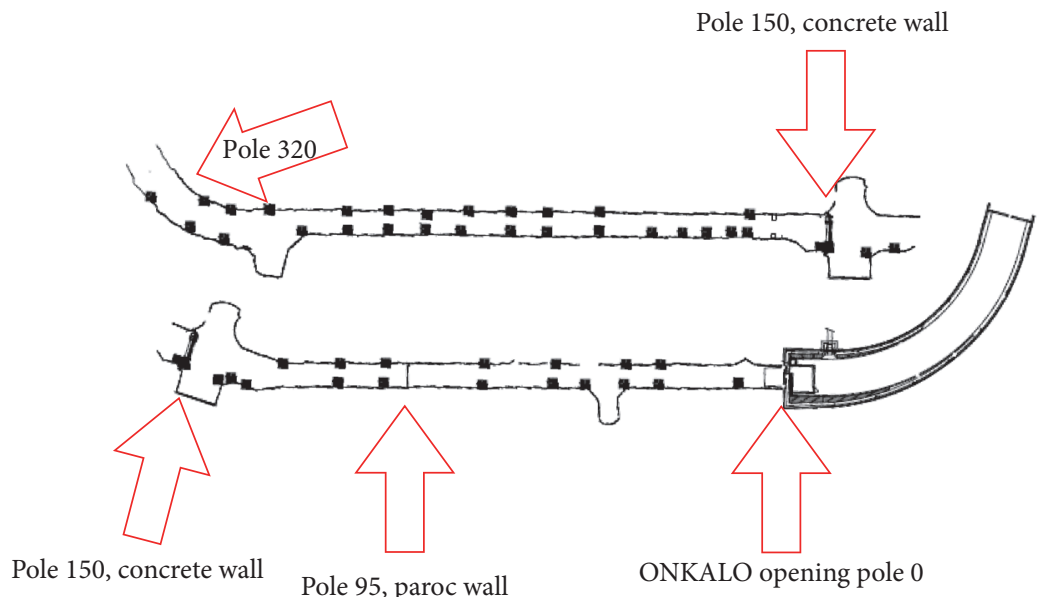

FIgURE 12: Measurement configuration 3.

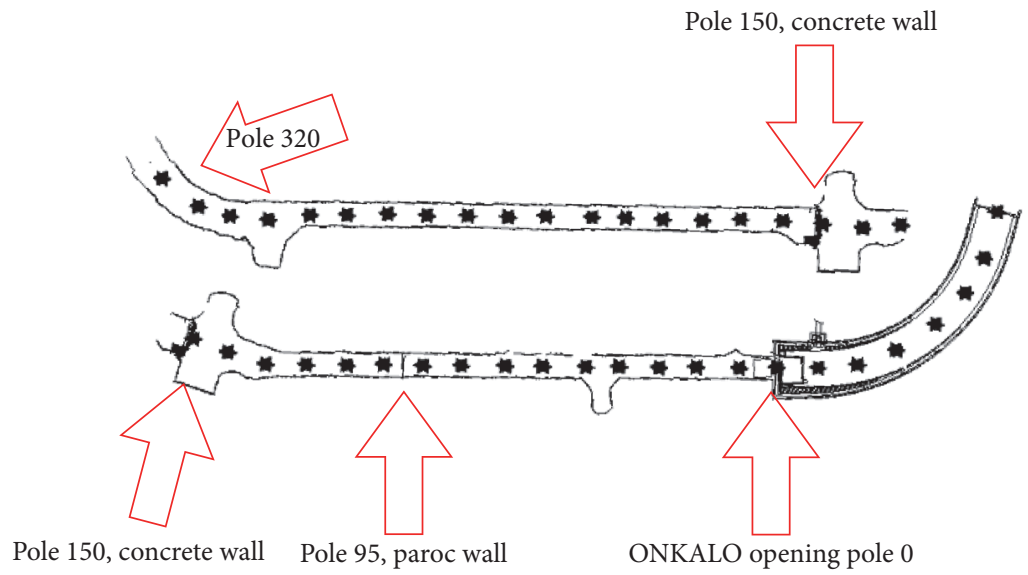

FIGURE 13: Measurement configuration 4.

A chart was made from identified tags where RSSI was marked. Also the pole number where the tag was and the tags distance to the antenna was recorded. From this data it was possible to determine the MRRR (maximum reliable read range) of all antennas. From the produced table all read safety cones were marked on the ONKALO layout. From this, every antenna MRRR range could be marked, that is, the range that the antenna could read all tags at the pole.

\section{Measurement Results}

The measurements for this study were carried out in autumn 2014. Antenna cable connections, possible damage to antennas or wiring, and surrounding conditions affect the antenna reading area measurements. The antennas were installed during 2010 and cabling and connections of Antenna 1 and Antenna 5 were originals. The cable for Antenna 2 has been changed in 2012 when a vehicle hit the antenna and caused it to drop, also damaging the cable. During the measurements, the temperature was $11^{\circ} \mathrm{C}$ and the relative humidity level was $99 \%$. Condensation gathered on walls and antennas.
6.1. Antenna 1. Antenna 1 is the in-reading antenna of the ONKALO tunnel system (Figure 16). This antenna is the most important antenna in the system, due to personnel safety reasons. After the reading of this antenna, the person is logged into the ONKALO system.

The measurement results of this antenna give a clear picture of the antenna MRRR. As the results can be compared to results of antennas 2 and 5, it can be seen that the PAROC walls affect the measurements results of the rear area.

In Figure 16, antenna 1 MRRR area is shown. This indicates the reliable value area starts from pole +5 . In the circled area in Figure 16, the RSSI was at its highest at poles 60-70. In Figure 17 you can see how antenna 1 reads from outside the tunnel at the centerline and left side. The left side of the reading area reaches up to $55 \mathrm{~mm}$ from the ONKALO opening. Figure 18 shows antenna 1 rear reading area. This figure shows how well the PAROC wall dampens the rear area. The rear area is nearly symmetrical.

Antenna 1 measurement occurrence table values have been summarized to Table 1 . On the left side of the table are the measurements of the left side of the tunnel, in the 


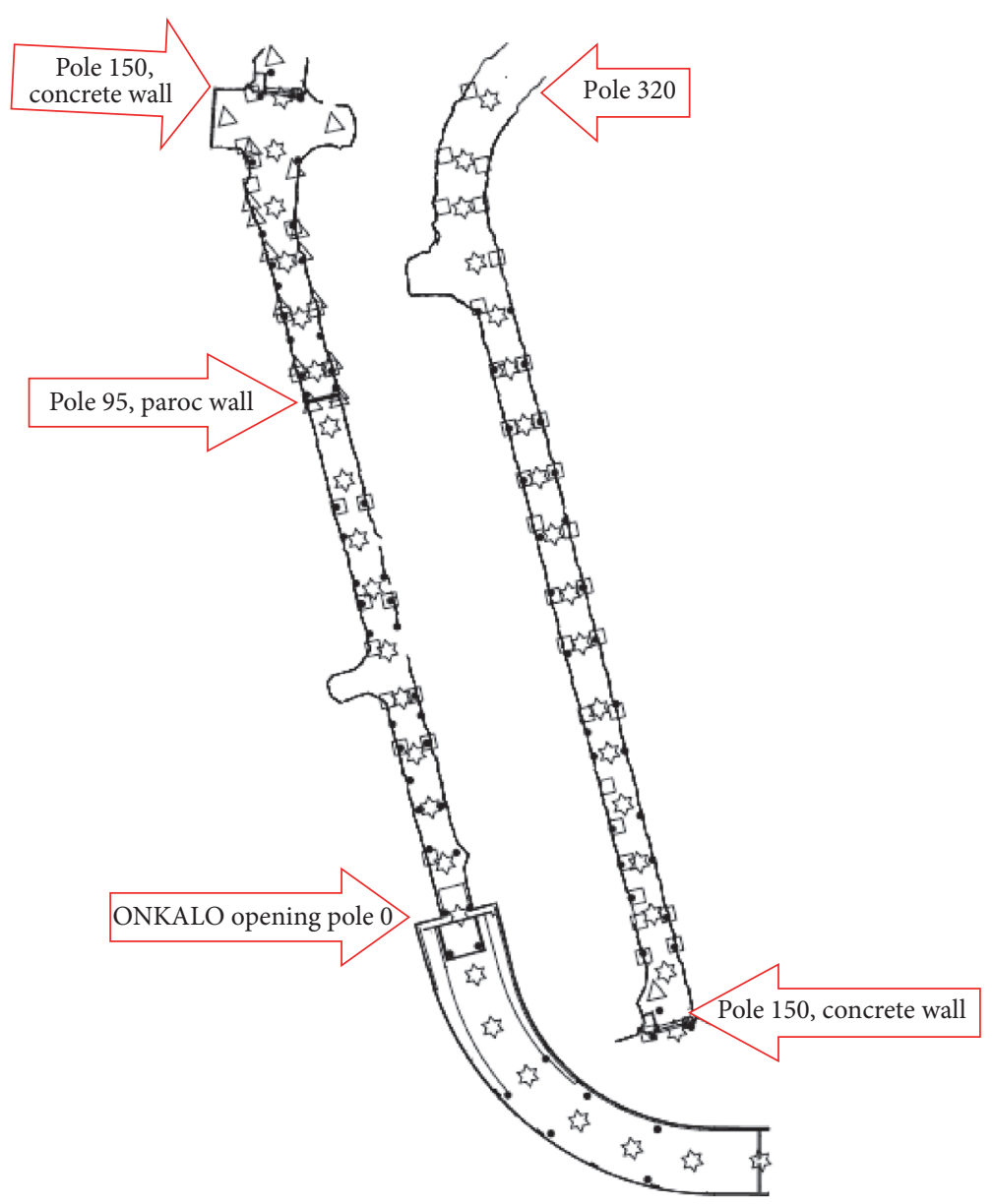

FIGURE 14: Measurement configurations 1-4.

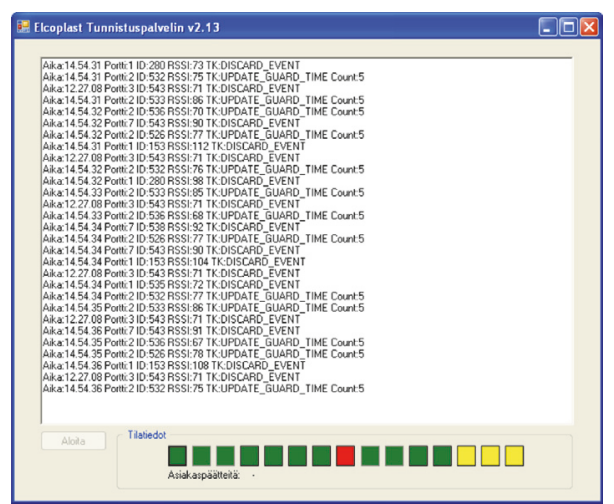

FIGURE 15: An example of a print screen screenshot file.

center are the measurements from the centerline, and on the right are the measurements of the right side. Pole indicates at what pole number the ID tag was when measured. Distance means the direct distance to the antenna. The RSSI value is the average of the measured values. As an example, the line VS135, $529,-40,314,69,5$ means that the ID tag 529 was at the left side at pole 135 and its direct distance to the antenna was $-40,314$ meters. The "-" here indicates that the ID tag was below the antenna. The number 69,5 is the average RSSI value collected from the documents. In the table, the antenna's MRRR area is limited to Italics.

6.2. Antenna 2. Antenna 2 is the second out of ONKALO tunnel reading antenna and it is the "main antenna" for outreading (Figure 19). The measurements of this antenna show how the MRRR area, that is, the reliable reading values 


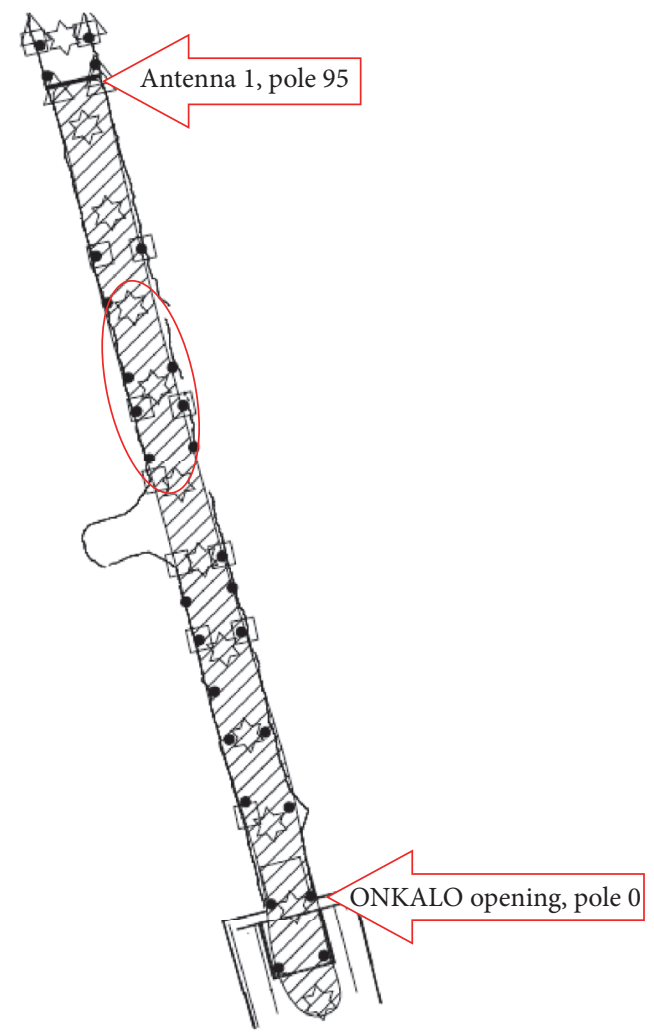

FIGURE 16: Antenna 1 MRRR area.

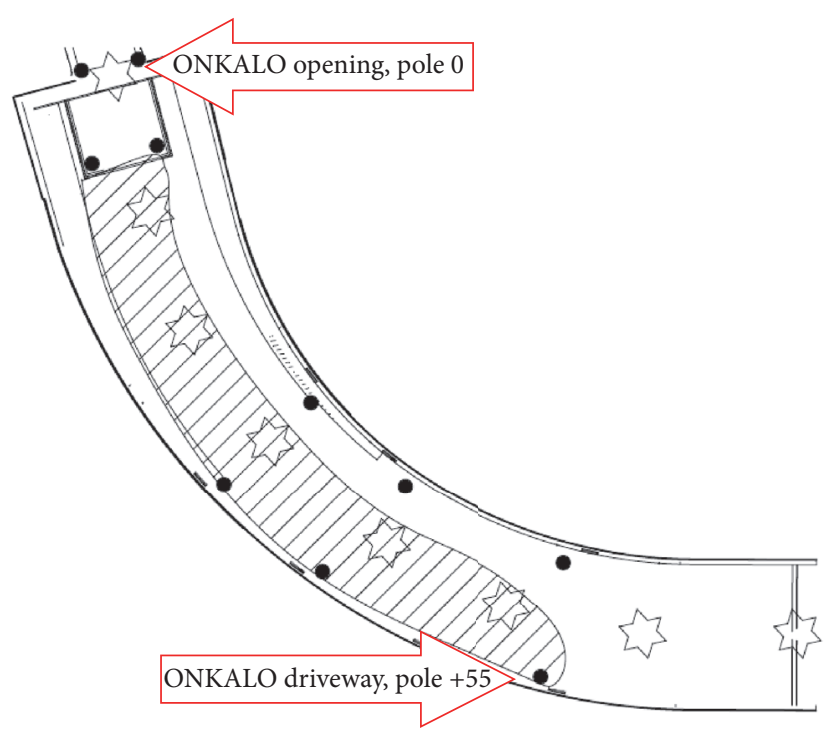

FIGURE 17: Antenna 1 front reading area.

area, changes after equipping the walls. Equipping in this case means installing electricity and instrument housings, water pipes, and other structures. The MRRR area reaches pole 208. There is no wall directly behind antenna 2 , which can be seen from the measurement results.

Antenna 2 measurement values have been summarized in Table 2. This table is read similarly to Table 1 . Figure 19 shows how antenna 2 MRRR area goes from pole 208 upwards. The ID tag at pole 200 is not read, which can be only explained by measurement failure, as all other tags were readable. ID tags on the sides at the same pole number had an RSSI value over 90.

In Figure 20, it can be seen how antenna 2 reads up to pole 311. It is also evident how equipping the wall causes reflections 


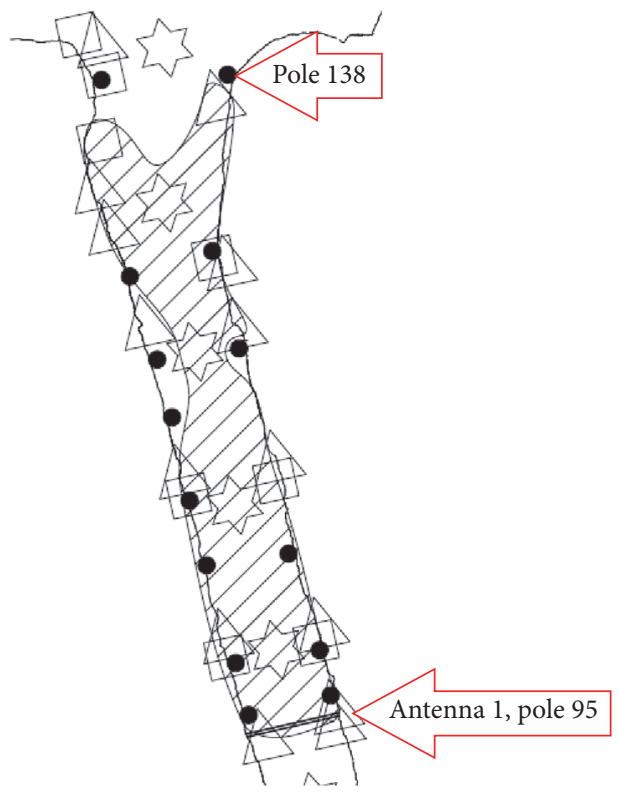

FiguRE 18: Antenna 1 rear reading area.

TABLE 1: Compiled table of antenna 1 measurements.

\begin{tabular}{|c|c|c|c|c|c|c|c|c|c|c|c|}
\hline Pole & Tag & Distance & RSSI & Pole & Tag & Distance & RSSI & Pole & Tag & Distance & RSSI \\
\hline VS 135 & 529 & $-40,314$ & 69,5 & & & & & OS 138 & 542 & $-40,138$ & 65,5 \\
\hline VS 130 & 541 & $-37,094$ & 69 & 130 & 536 & $-35,18$ & 67,5 & & & & \\
\hline \multirow{2}{*}{ VS 125} & 532 & $-31,495$ & 67 & & & & 0 & OS 125 & 531 & $-30,794$ & 71,5 \\
\hline & & & & 120 & 526 & $-25,437$ & 68,5 & OS 120 & 530 & $-25,279$ & 80,5 \\
\hline VS 110 & 543 & $-17,822$ & 83 & 110 & 532 & $-15,256$ & 74,5 & OS 110 & 542 & $-16,964$ & 80 \\
\hline VS 100 & 541 & $-7,813$ & 80,5 & 100 & 533 & $-5,942$ & 78 & OS 100 & 531 & $-5,176$ & 89 \\
\hline \multirow[t]{2}{*}{ VS 95} & 532 & $-4,854$ & 106,5 & 90 & 536 & 5,38 & 107 & OS 95 & 540 & 0 & 104,5 \\
\hline & & & & 80 & 526 & 14,649 & 117,5 & & & & \\
\hline VS 75 & 529 & 19,426 & 118,5 & & & & 0 & OS 75 & 531 & 19,231 & 111,5 \\
\hline VS 70 & 533 & 26,657 & 111,5 & 70 & 532 & 25,337 & 115 & & & & \\
\hline VS 61 & 530 & 32,988 & 113 & 60 & 533 & 34,431 & 100,5 & OS 61 & 532 & 32,849 & 107,5 \\
\hline VS 57 & 529 & 36,584 & 111,5 & & & & & OS 57 & 531 & 37,061 & 95 \\
\hline VS 50 & 533 & 44,606 & 94,5 & 50 & 536 & 45,62 & 100 & OS 53 & 532 & 41,839 & 104 \\
\hline VS 35 & 530 & 58,361 & 99 & 40 & 526 & 54,287 & 83,5 & OS 40 & 531 & 54,487 & 79 \\
\hline VS 30 & 529 & 62,773 & 95,5 & 30 & 532 & 64,344 & 94 & OS 30 & 531 & 63,063 & 92,5 \\
\hline VS 20 & 530 & 74,084 & 85 & 20 & 533 & 74,187 & 97,5 & OS 20 & 532 & 74,285 & 94,5 \\
\hline VS 15 & 529 & 82,725 & 77 & 10 & 536 & 84,431 & 86,5 & OS 15 & 531 & 82,845 & 91 \\
\hline VS 0 & 530 & 93,395 & 98,5 & 0 & 526 & 93,852 & 90,5 & OS 0 & 532 & 93,17 & 94,5 \\
\hline \multirow[t]{2}{*}{$V S+5$} & 530 & 100,268 & 93 & +10 & 532 & 104,776 & 72,5 & $O S+5$ & 532 & 99,874 & 74 \\
\hline & & & & +20 & 533 & 114,695 & 72,5 & & & & \\
\hline $\mathrm{VS}+30$ & 529 & 126,534 & 65 & +30 & 536 & 124,376 & 73,5 & & & & \\
\hline $\mathrm{VS}+40$ & 530 & 135,669 & 68 & +40 & 526 & 136,067 & 67,5 & & & & \\
\hline $\mathrm{VS}+55$ & 529 & 148,841 & 71,5 & +50 & 532 & 146,694 & 67 & & & & \\
\hline
\end{tabular}

that affect the reading. Antenna 2 rear reading point reached all the way to pole 17 (see Figure 21) but this was just one single point. More points near this, where a reading had occurred, could not be found. Thus, it was considered to have happened due to dispersion. The next closest reading point was at pole 58. It can be seen that the fact that there is no signal dampening material behind the antenna affects the rear reading area, as does the PAROC wall door opening at pole 105.

6.3. Antenna 5. The main purpose of antenna 5 installation is to verify the readings of antenna 2 . This antenna has been 
TABLE 2: Compiled table of antenna 2 measurements.

\begin{tabular}{|c|c|c|c|c|c|c|c|c|c|c|c|}
\hline Pole & tag & Distance & RSSI & Pole & tag & Distance & RSSI & Pole & $\operatorname{tag}$ & Distance & RSSI \\
\hline \multirow[t]{4}{*}{ VS 311} & 526 & 146,775 & 69,5 & & & & & & & & \\
\hline & & & & 290 & 536 & 127,216 & 67 & OS 290 & 532 & 127,261 & 66,5 \\
\hline & & & & & & & & OS 280 & 531 & 117,867 & 67 \\
\hline & & & & 270 & 532 & 107,788 & 67 & OS 270 & 533 & 107,985 & 71 \\
\hline \multirow[t]{2}{*}{ VS 260} & 526 & 97,523 & 66,5 & & & & & OS 260 & 532 & 97,56 & 74 \\
\hline & & & & & & & & OS 250 & 533 & 88,148 & 70,5 \\
\hline VS 240 & 526 & 77,697 & 73,5 & & & & & OS 240 & 532 & 77,772 & 67,5 \\
\hline VS 230 & 536 & 67,146 & 70 & 230 & 532 & 66,849 & 78,5 & & & & \\
\hline VS 220 & 526 & 58,025 & 75 & 220 & 533 & 57,713 & 72,5 & OS 220 & 532 & 58,133 & 76 \\
\hline VS 208 & 536 & 45,054 & 72 & 210 & 536 & 45,737 & 80,5 & OS 208 & 533 & 45,255 & 84 \\
\hline VS 200 & 529 & 37,812 & 90,5 & & & & & OS 200 & 530 & 38,12 & 93,5 \\
\hline VS 190 & 532 & 24,503 & 87,5 & 190 & 532 & 28,434 & 90,5 & OS 190 & 531 & 26,372 & 79,5 \\
\hline VS 180 & 529 & 18,088 & 88,5 & 180 & 533 & 18,028 & 94,5 & OS 180 & 530 & 18,146 & 92,5 \\
\hline \multirow[t]{2}{*}{ VS 170} & 532 & 7,901 & 95 & 170 & 536 & 8,709 & 114,5 & OS 170 & 531 & 8,933 & 105 \\
\hline & & & & 160 & 526 & $-3,165$ & 116,5 & & & & \\
\hline VS 150 & 532 & $-12,626$ & 85,5 & 150 & 532 & $-12,648$ & 110 & OS 150 & 531 & $-13,372$ & 99,5 \\
\hline VS 145 & 500 & $-16,819$ & 92,5 & & & & & OS 145 & 540 & $-16,896$ & 78 \\
\hline VS 140 & 529 & $-22,091$ & 85 & 140 & 533 & $-21,993$ & 92,5 & OS 140 & 530 & $-23,67$ & 100 \\
\hline VS 139 & 533 & $-24,317$ & 77,5 & 130 & 536 & $-31,92$ & 81 & OS 138 & 542 & $-22,825$ & 93 \\
\hline VS 120 & 533 & $-42,82$ & 75 & 120 & 526 & $-41,578$ & 86,5 & OS 120 & 542 & $-37,587$ & 82,5 \\
\hline VS 110 & 529 & $-50,271$ & 77,5 & 110 & 532 & $-51,676$ & 71 & OS 110 & 531 & $-49,846$ & 69,5 \\
\hline VS 105 & 533 & $-55,585$ & 82 & & & & & OS 105 & 530 & $-55,428$ & 71,5 \\
\hline VS 100 & 529 & $-61,236$ & 72 & 100 & 533 & $-61,157$ & 70 & OS 100 & 540 & $-57,309$ & 84,5 \\
\hline \multirow[t]{2}{*}{ VS 97} & 533 & $-65,029$ & 74 & 90 & 536 & $-71,231$ & 70 & OS 97 & 541 & $-62,438$ & 75,5 \\
\hline & & & & 80 & 526 & $-80,893$ & 66,5 & & & & \\
\hline VS 57 & 529 & $-102,843$ & 67 & 70 & 532 & $-91,608$ & 67,5 & & & & \\
\hline VS 17 & 533 & $-147,427$ & 70,5 & & & & & & & & \\
\hline
\end{tabular}

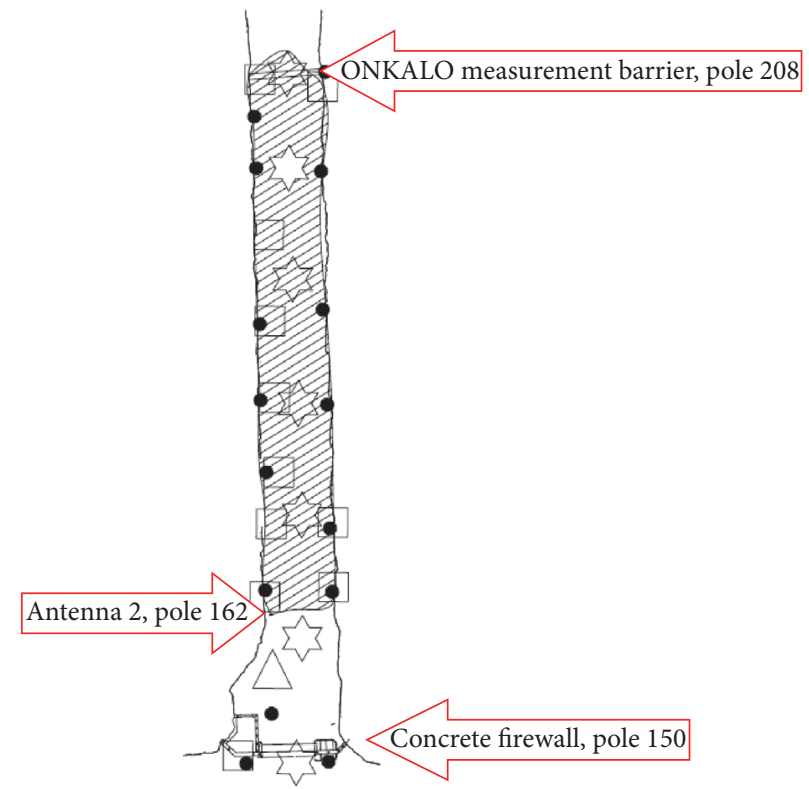

FIGURE 19: Antenna 2 MRRR area. 


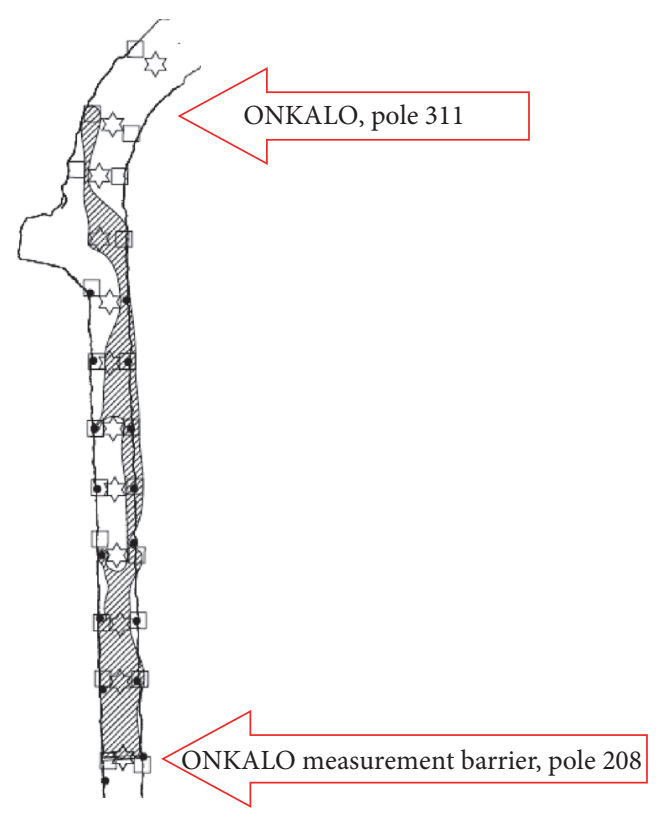

Figure 20: Antenna 2 front reading area.

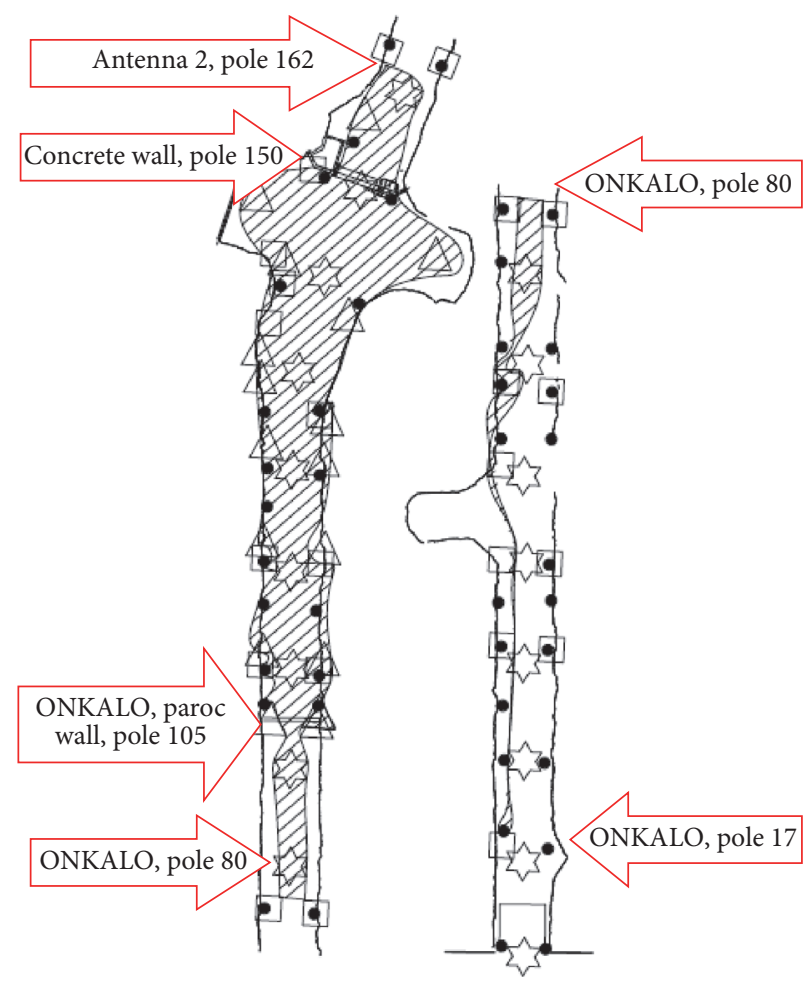

Figure 21: Antenna 2 rear reading area.

installed lower than the other antennas. The lower location is meant to ensure reading from delivery vans. The differences due to lower installation can be seen from the MRRR area results.

In Figure 22, it is shown that antenna 5 MRRR area reaches pole number 170 in the ONKALO tunnel. It can also be seen how much the antenna direction and height affect the MRRR area size. Figure 23 shows how antenna 5 reads the left side of the driveway up to pole 208. The antennas strong alignment over the center towards the left wall explains this result. Antenna 5 rear reading area is affected by the concrete wall located at pole 150 , as well as the door opening, which can be seen in Figure 23.

Antenna 5 measurement occurrence table values have been summarized in Table 3, which can be read similarly to Tables 1 and 2. 


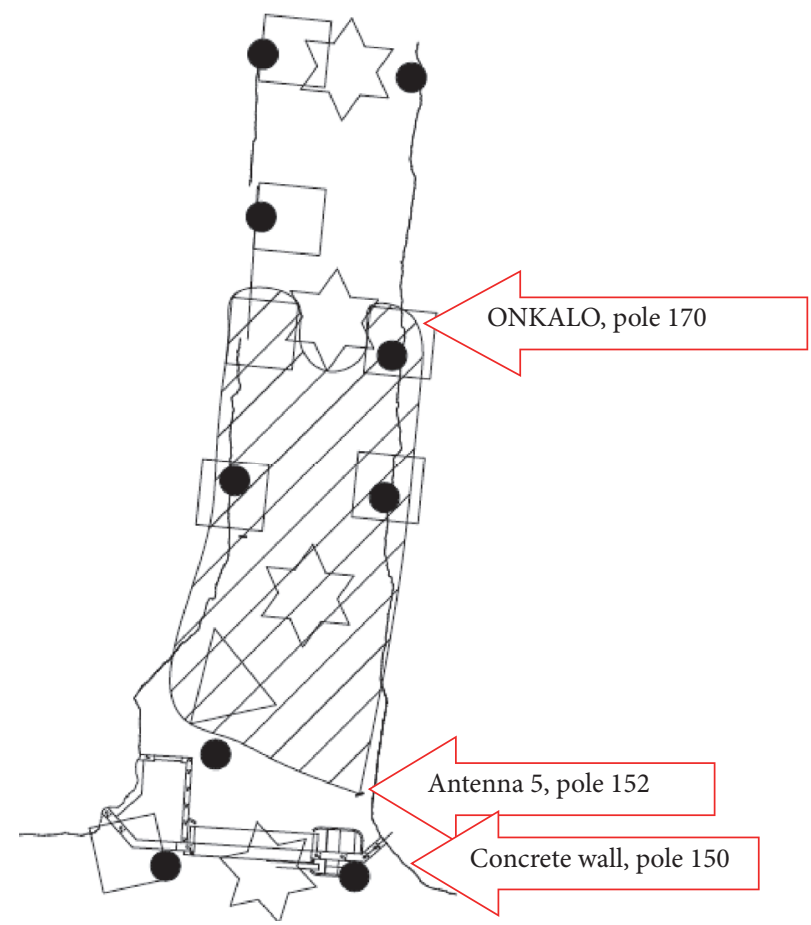

FIgURE 22: Antenna 5 MRRR area.

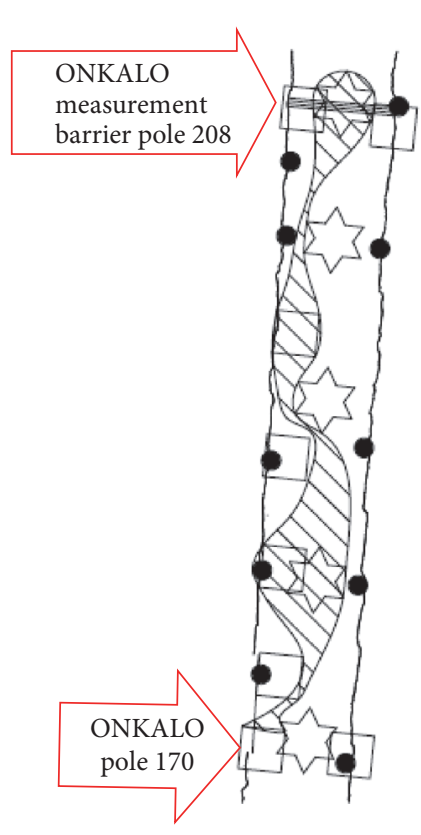

(a)

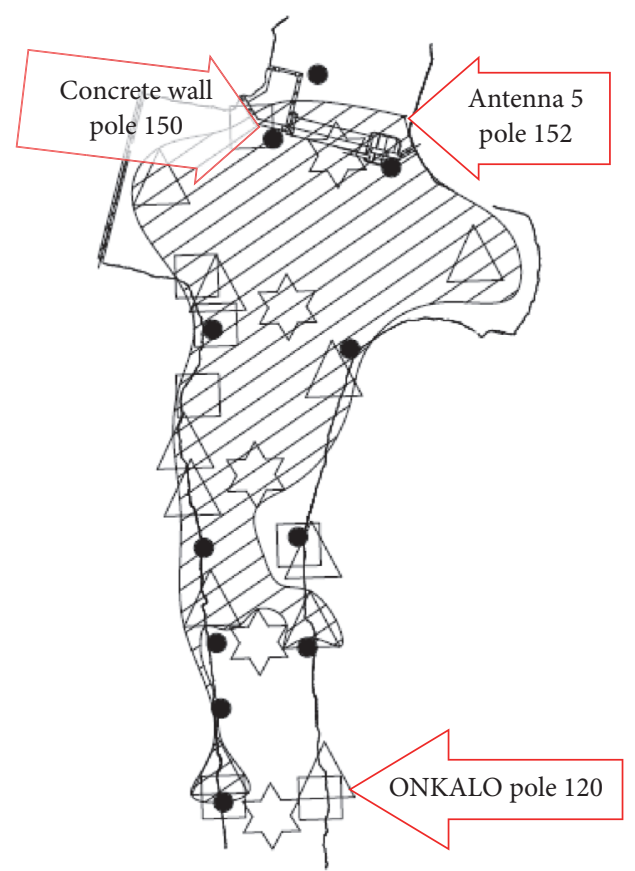

(b)

FIGURE 23: Antenna 5 front reading area (a) and rear reading area (b).

6.4. Further Discussion. In general, the features that affect the antenna reading area size are antenna direction, dampening from obstacles, reflections, diffraction dampening, dispersion dampening, and fading. Based on our measurement results, obstacles, dispersion, and reflection are the main features affecting the antenna reading area in a tunnel environment.

The effect of dampening because of obstacles can be seen from the antenna front to rear balance. Also the antenna direction can be seen affecting the dampening. From antenna 2 
TABLE 3: Compiled table of antenna 5 measurements.

\begin{tabular}{|c|c|c|c|c|c|c|c|c|c|c|c|}
\hline Pole & Tag & Distance & RSSI & Pole & Tag & Distance & RSSI & Pole & Tag & Distance & RSSI \\
\hline VS 195 & 533 & 41,647 & 70 & & & & & & & & \\
\hline VS 180 & 529 & 27,88 & 70,5 & 180 & 533 & 27,371 & 73,5 & & & & \\
\hline VS 170 & 532 & 17,877 & 83 & & & & & OS 170 & 531 & 16,879 & 70 \\
\hline VS 165 & 529 & 12,486 & 84 & 160 & 526 & 7,771 & 77 & OS 165 & 530 & 11,391 & 86 \\
\hline VS 150 & 541 & $-8,966$ & 72,5 & 150 & 532 & $-4,585$ & 94,5 & OS 150 & 531 & $-3,268$ & 92,5 \\
\hline VS 145 & 500 & $-15,276$ & 75,5 & & & & & OS 145 & 542 & $-9,059$ & 76,5 \\
\hline VS 140 & 500 & $-15,595$ & 91 & 140 & 533 & $-13,203$ & 86,5 & OS 140 & 530 & $-13,803$ & 85 \\
\hline VS 139 & 533 & $-16,591$ & 90 & & & & & OS 138 & 542 & $-15,757$ & 73,5 \\
\hline VS 135 & 529 & $-20,76$ & 84,5 & & & & & & & & \\
\hline VS 130 & 543 & $-23,257$ & 77 & 130 & 536 & $-22,728$ & 69 & & & & \\
\hline VS 125 & 532 & $-27,591$ & 70 & & & & & & & & \\
\hline VS 128 & 500 & $-25,276$ & 79 & & & & & & & & \\
\hline VS 122 & 543 & $-30,894$ & 77,5 & & & & & OS 120 & 542 & $-30,51$ & 72 \\
\hline VS 110 & 543 & $-40,046$ & 67 & & & & & & & & \\
\hline
\end{tabular}

measurement results, it can be seen that the effect of the door opening in the rear reading area on the left of the driveway is larger than in the front area (see Figures 20 and 21). The wall behind antenna 1 causes uniform dampening along the driveway of the rear reading area.

The ONKALO walls are coarse due to drilling and blasting. The coarse wall surface causes surprising reflections and dispersion especially at the so-called breaks, which means the junction of two blasting areas. An example of dispersion can be seen at the rear reading area of antenna 2. The antenna managed to read a tag at its rear reading area from 147 meters.

Reflection can be seen in ONKALO in a way that in some areas reading of tags does not follow common order (Figures 20,21 , and 23), and this definitely requires further research. Diffraction dampening or fading do not have a noticeable effect in this implementation and it was not studied in this case. The configurations were built so that the antennas and tags had a clear visual contact to the readers.

\section{Conclusion}

In this study, the effects of RFID antenna location and direction on the antenna reading area size were studied in an underground access monitoring system. In addition to antenna location and direction, also absorption to obstacles, reflections, diffraction, scattering, and refraction affect the antenna reading area.

The irregularities of the reading areas showed the need for further research, which means that the tunnel rock surfaces need to be studied and possible water leakages need to be located, in order to examine their effects on the reading area size.

Before future measurements, also the collection of data will be improved. All measurement results will be saved to a database. In addition, measurements will be made so that there are tags at different heights. Based on these measurements, it will be possible to define the best antenna direction and location.

\section{Conflicts of Interest}

The authors declare that there are no conflicts of interest regarding the publication of this paper.

\section{References}

[1] P. Misra, S. Kanhere, D. Ostry, and S. Jha, "Safety assurance and rescue communication systems in high-stress environments: a mining case study," IEEE Communications Magazine, vol. 48, no. 4, pp. 66-73, 2010.

[2] T. Saanio, A. Ikonen, P. Keto et al., "Design of the Disposal Facility 2012," Working Report 2013-17, Posiva Oy, Eurajoki, Finland, 2012.

[3] Z. Shi, Y. Li, and Q. Gu, "Based on TWA adaptive centroid wireless localization algorithm of area in underground mine," Advances in Information Sciences and Service Sciences, vol. 4, no. 19, pp. 191-196, 2012.

[4] L. Bai-Ping, L. Shang, L. Wen-Feng, and L. Chen, "Research on coal mine personnel orientation rescuing system based on RFID," in Proceedings of the International Conference on MultiMedia and Information Technology (MMIT '08), pp. 555557, Three Gorges, China, December 2008.

[5] A. Wang and Y. Lu, "The design and implementation of mine workers' precise location system," in Proceedings of the 2 nd Conference on Environmental Science and Information Application Technology (ESIAT '10), pp. 303-305, Wuhan, China, July 2010.

[6] U. Farooq, K. M. Hasan, F. Rafiq, and M. U. Asad, "An integrated approach towards designing an embedded wireless monitoring and access control system using RFID and MMS technologies," in Proceedings of the 16th International Multi Topic Conference (INMIC '13), pp. 182-188, Lahore, Pakistan, December 2013.

[7] C. Hurjui, C. Turcu, and A. Graur, "Management system of the products on warranty based on RFID technologies," in Proceedings of the 11th International Conference on Optimization of Electrical and Electronic Equipment (OPTIM '08), pp. 231-236, IEEE, Brașov, Romania, May 2008.

[8] A. Mai, Z. Wei, and M. Gao, "An access control and positioning security management system based on RFID," in Proceedings of the 7th International Conference on Intelligent Human-Machine 
Systems and Cybernetics (IHMSC '15), pp. 537-540, Hangzhou, China, August 2015.

[9] J. Landt, “The history of RFID," IEEE Potentials, vol. 24, no. 4, pp. 8-11, 2005.

[10] P. Nikitin, "Leon Theremin (Lev Termen)," IEEE Antennas and Propagation Magazine, vol. 54, no. 5, pp. 252-257, 2012.

[11] R. Want, "An introduction to RFID technology," IEEE Pervasive Computing, vol. 5, no. 1, pp. 25-33, 2006.

[12] D. Dobkin, The RF in RFID: Passive UHF RFID in Practice, Newnes-Elsevier, Netherland, Amsterdam, 2008.

[13] Z. Sun and I. F. Akyildiz, "Optimal MIMO antenna geometry analysis for wireless networks in underground tunnels," in Proceedings of the IEEE Global Telecommunications Conference (GLOBECOM '09), pp. 1-6, Honolulu, Hawaii, USA, December 2009.

[14] L. Sydanheimo, M. Keskilammi, and M. Kivikoski, "Reliable mobile computing to underground mine," in Proceedings of the IEEE International Conference on Communications (ICC '00), pp. 882-888, June 2000.

[15] K. Kordelin, J. Kordelin, M. Johansson, J. Virkki, L. Ukkonen, and L. Sydänheimo, "Development and implementation of an RFID-based tunnel access monitoring system," Science and Technology of Nuclear Installations, vol. 2016, Article ID 9897675, 10 pages, 2016.

[16] Paroc Web-pages, 2016, http://www.paroc.com. 


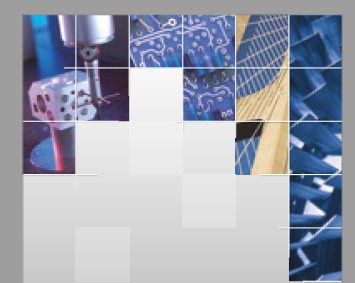

\section{Enfincering}
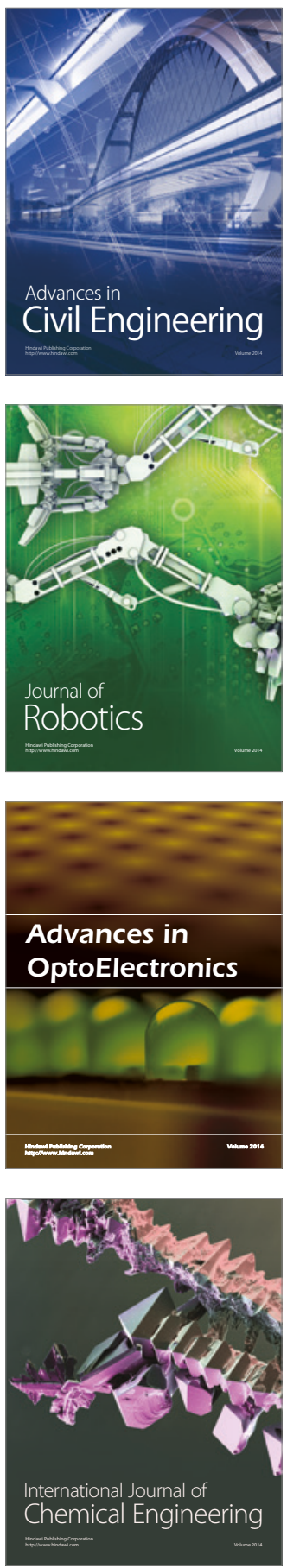

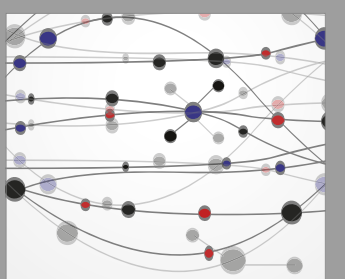

The Scientific World Journal

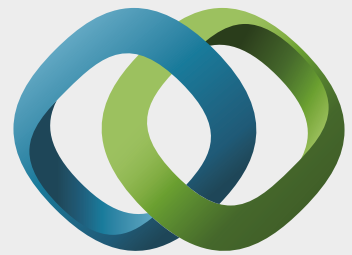

\section{Hindawi}

Submit your manuscripts at

https://www.hindawi.com
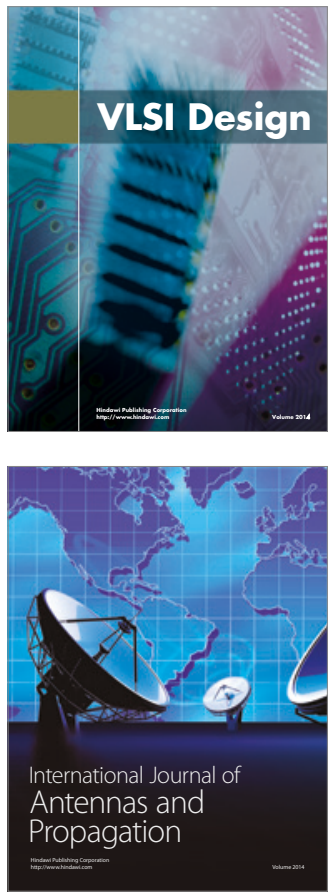

\section{Rotating}

Machinery
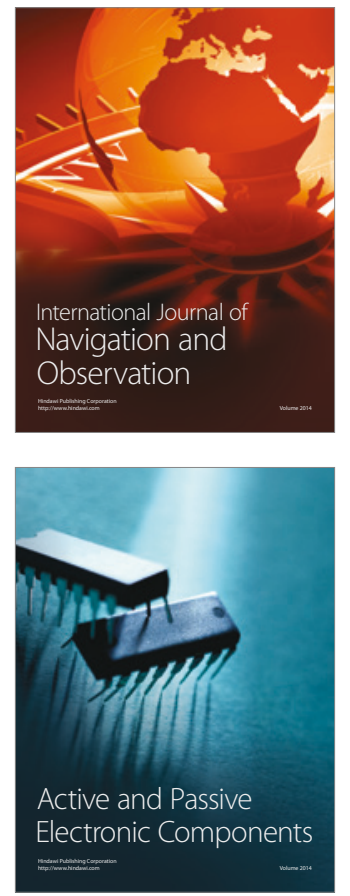
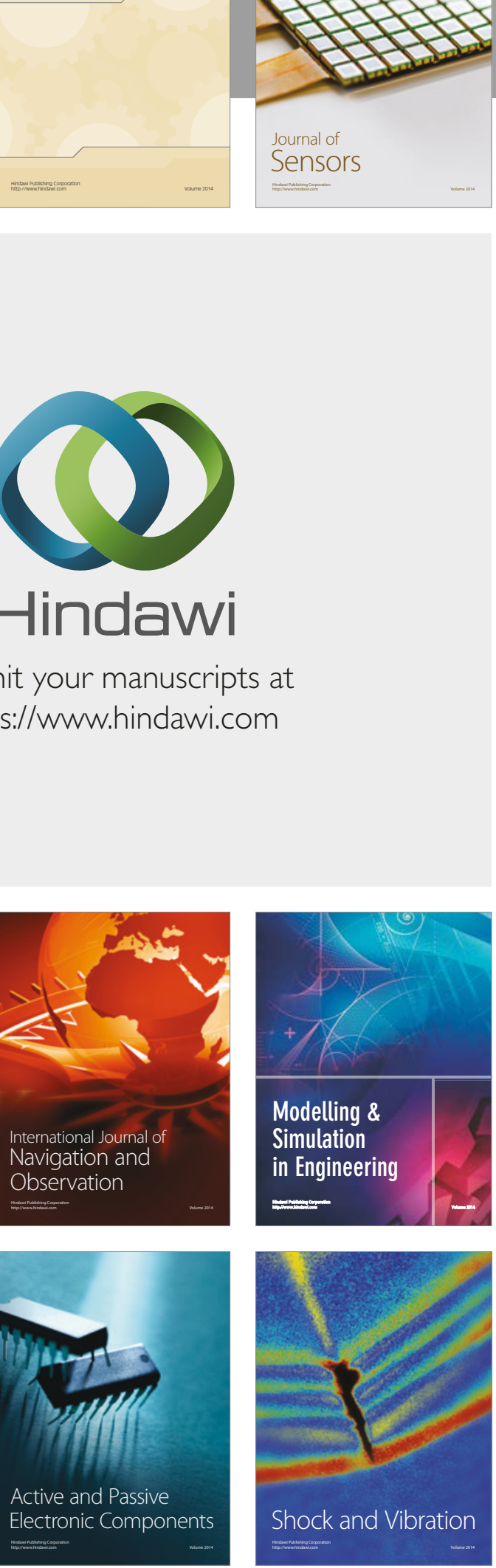
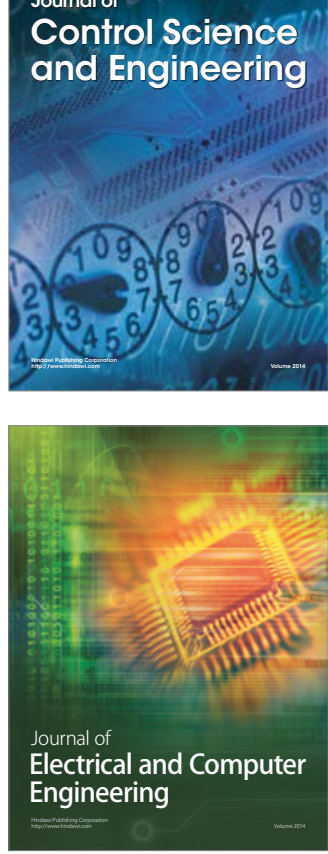

Distributed

Journal of

Control Science

and Engineering
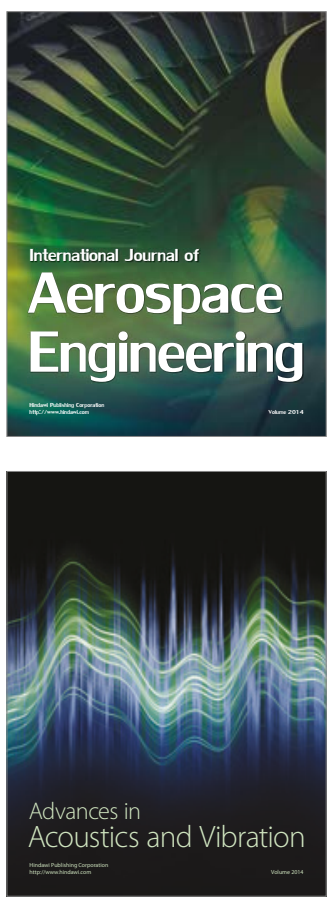

Sensor Networks 